\section{VACINA CONTRA HEPATITE B}

Autoria: Sociedade Brasileira de Pediatria

Participante: Scaramuzzi DR

Método de coleta de evidências: Revisão sistemática da literatura, utilizando os dados dos seguintes bancos: Medline, Lilacs, Cochrane Reviewers, no período de 1980 a 2000.

Graus de recomendação e força de evidência científica:

A: Estudos experimentais e observacionais de melhor consistência.

B: Estudos experimentais e observacionais de menor consistência.

C: Relatos de casos (estudos não controlados).

D: Opinião desprovida de avaliação crítica, baseada em consensos, estudos fisiológicos ou modelos animais.

Conflito de interesse: Nenhum conflito de interesse declarado.

As vacinas contra a hepatite $B$ disponíveis no Brasil são produzidas por engenharia genética por meio da inserção de um plasmídeo contendo o antígeno de superfície do vírus $B$ (AgHBs) em levedura. As vacinas não promovem infecção, pois não contêm DNA viral. A vacinação induz apenas à produção do anti-HBs. As vacinas podem conter ou não timerosal'(D) e o AgHBs é adsorvido ao hidróxido de alumínio. Também estão disponíveis formulações combinadas com outras vacinas.

Devem ser conservadas em geladeira, entre $20^{\circ} \mathrm{C}$ e $80^{\circ} \mathrm{C}$, e não podem ser congeladas, pois perdem sua potência.

Os esquemas posológicos variam de acordo com o laboratório produtor.

Os esquemas mais utilizados freqüentemente são de três doses nos momentos zero, um e seis meses após a primeira dose. $O$ intervalo recomendado entre a primeira e a segunda dose é de um mês, e entre a segunda e terceira é de, no mínimo, dois meses. A terceira dose deve ser administrada após os seis meses de idade. Se a vacinação for interrompida, não é necessário recomeçar o esquema, apenas completá-lo ${ }^{2,3}(\mathbf{D})$.

Em recém-nascidos e lactentes, as vacinas devem ser aplicadas por via intramuscular no músculo ântero-lateral da coxa e em crianças maiores, adolescentes e adultos, no deltóide ${ }^{2-4}(\mathbf{D})$.

\section{Imunogenicidade e eficácia}

Os títulos de anti-HBs considerados protetores são superiores a $10 \mathrm{mUl} / \mathrm{ml}$. Após três doses intramusculares de vacina contra hepatite B, mais de $90 \%$ dos adultos jovens e mais de $95 \%$ das crianças e adolescentes desenvolvem respostas adequadas de anticorpos. Porém, com a idade, ocorre queda da imunogenicidade e, aos 60 anos, aproximadamente, somente cerca de $75 \%$ dos vacinados desenvolvem anticorpos protetores ${ }^{3}(\mathbf{D})$.
Os fatores que podem afetar a resposta à vacina incluem: modo de conservação da vacina, local da aplicação, sexo, idade, peso maior que $70 \mathrm{~kg}$, obesidade, fumo, fatores genéticos, doenças crônicas e condição nutricional e imunológica ${ }^{3}(\mathbf{D})$.

Devido à excelente imunogenicidade da vacina, não está indicada sorologia após a vacinação, exceto para os grupos de risco, tais como: profissionais da saúde, pacientes em diálise e recém-nascidos de mães portadoras do AgHBs. Nesse caso, o teste sorológico deve ser realizado um a três meses após completar o esquema vacinal ${ }^{3}(\mathbf{D})$.

Com o tempo, os títulos de anticorpos podem cair e até se tornar indetectáveis; porém, a proteção contra doença sintomática e infecção crônica persiste. As pessoas que responderam à vacina apresentam resposta anamnéstica quando em contato com o vírus, demonstrando que as vacinas induzem memória imunológica, por isso, até o momento, não se recomenda revacinação de pessoas imunocompetentes ${ }^{1,2}(\mathbf{D})$.

A vacina tem eficácia de $80 \%$ a 100\% em prevenir a infecção ou a doença clínica naqueles que recebem o esquema completo $^{2,3,5}(\mathbf{C})$.

Em Taiwan, país de alta endemicidade da hepatite B, oito anos após o início da imunização universal, houve redução de cinco vezes na porcentagem de crianças AgHBs positivas. A eficácia protetora da vacina foi de $85 \%{ }^{5}(\mathbf{C})$. Houve diminuição significativa nos índices de mortalidade por hepatocarcinoma em crianças no mesmo país entre 1984 (época do início da vacinação) e 19936(B).

No Alaska, região de alta endemicidade de hepatite $B$, dez anos após a implantação da imunização universal dos lactentes, entre 27 I crianças menores de dez anos imunizadas, nenhuma ficou portadora crônica, e apenas quatro mostravam evidência de infecção pregressa resolvida, sugerindo que a vacinação universal pode levar à eliminação de novos casos de infecção $\operatorname{crônica}^{\top}(\mathbf{C})$.

\section{Eventos adversos}

Os eventos adversos mais comuns são a dor no local da aplicação (3\% a 29\%) e febre baixa (1\% a 6\%); são mais freqüentes em adultos que em crianças nas primeiras doses e tendem a desaparecer em 24 a $48 \operatorname{horas}^{3}(\mathbf{D})$.

Raramente podem ocorrer reações alérgicas. A incidência de anafilaxia é de, aproximadamente, I/600.000 aplicações $^{4,8}(\mathbf{D})$.

Uma revisão da literatura mundial sobre eventos adversos às vacinas recombinantes, desde a sua introdução, concluiu que o número de eventos adversos é muito pequeno comparado ao grande número de vacinados, correspondendo a um para I 5.500 doses distribuídas. Os benefícios obtidos com a vacina superam em muito os raros riscos de eventos adversos ${ }^{8}(\mathbf{D})$.

\section{Indicações}

As vacinas estão indicadas de forma universal para todas as crianças e adolescentes e para adultos pertencentes aos grupos 
de risco: politransfundidos, pacientes submetidos à diálise, profissionais da saúde, contactantes domiciliares com portador crônico, parceiro sexual de portador crônico, usuários de drogas injetáveis, pessoas de vida sexual promíscua, imigrantes de áreas endêmicas ${ }^{1-3}(\mathbf{D})$.

Os recém-nascidos de mães portadoras do vírus B têm grande risco de adquirir a infecção ao nascer e, destes, 90\% evoluem para doença crônica. Para prevenir a transmissão ao recém-nascido é muito importante que a vacina contra hepatite B seja aplicada universalmente em todos os recém-nascidos, rotineiramente, logo após o nascimento, nas primeiras 12 a 24 horas de vida. Quando a mãe for $\mathrm{HBeAg}$ positiva, é possível, embora não esteja provado, que o uso adicional e simultâneo de imunoglobulina hiperimune contra hepatite B confira pequeno aumento na proteção. É muito importante que o esquema vacinal seja completado com mais duas doses um e seis meses após a primeira. No caso de gestantes AgHBs positivas, que sejam também HIV positivas, ou se a criança nascer com $2.000 \mathrm{~g}$ ou menos, ou 34 semanas de gestação ou menos, além da vacina, recomenda-se a imunoglobulina hiperimune contra hepatite $\mathrm{B}^{4,9-11}(\mathbf{D})^{12-14}(\mathbf{C})^{15}(\mathbf{A})$.

Para os recém-nascidos de mães positivas para o $\mathrm{AgHBs}$, não há contra-indicação ao aleitamento materno, desde que sejam adequadamente imunizados ${ }^{4}(\mathbf{D})^{15}(\mathbf{A})$.

\section{Contra-indicações}

As contra-indicações à vacina são restritas. Pessoas que apresentaram reações graves após a vacinação, tais como anafilaxia, não devem continuar o esquema.

Em gestantes e nutrizes, se houver justificativa, a vacina pode ser administrada ${ }^{2-4}(\mathbf{D})$.

\section{Referências}

I.Centers for Disease Control and Prevention Update: expanded availability of thimerosal preservative: free hepatitis B vaccine. MMWR Morb Mortal Wkly Rep. 2000;49:642-51.

2.American Academy of Pediatrics. 2000 Red Book. Report of the Committee on Infectious Diseases. 25 $5^{\text {th }}$ ed. Elk Grove Village: American Academy of Pediatrics; 2000.

3.Centers for Disease Control and Prevention. Epidemiology and prevention of vaccine-preventable diseases. $7^{\text {th }}$ ed. Atlanta; 2002

4.Ministério da Saúde. Manual dos centros de referência de imunobiológicos especiais. Brasília: Fundação Nacional de Saúde; 200 I . p.59-63.

5.Wong WC, Tsang KK. A mass hepatitis B vaccination programme in Taiwan: its preparation, results and reasons for uncompleted vaccinations. Vaccine. 1994; 12:229-34.

6.Lee CL, Ko YC. Hepatitis B vaccination and hepatocellular carcinoma in Taiwan. Pediatrics. 1997;99:351-3.

7.Harpaz R, McMahon BJ, Margolis HS, Shapiro CN, Havron D, Carpenter G, et al. Elimination of new chronic hepatitis B virus infections: results of the Alaska immunization program. | Infect Dis. 2000; 181:413-8.

8. Grotto I, Mandel Y, Ephros M, Ashkenazi I, Shemer J. Major adverse reactions to yeast-derived hepatitis B vaccines: a review. Vaccine. 1998; 16:329-34.

9.Assad S, Francis A. Over a decade of experience with a yeast recombinant hepatitis B vaccine. Vaccine. 1999; I 8:57-67.

10.Mahoney FJ, Kane M. Hepatitis B Vaccine. In: Plotkin AS, Orenstein WA. editors. Vaccines. 3rd ed. Philadelphia: Saunders; 1999. p. 169-70.

I I.Centers for Disease Control and Prevention. Recommendations of the Immunization Practices Advisory Committee. Prevention of perinatal transmission of hepatitis B virus: prenatal screening of all pregnant women for hepatitis B surface antigen. MMWR Morb Mortal Wkly Rep. 1 988;37:34 I -6.

12.Zamir C, Dagan R, Zamir D, Rishpon S, Fraser D, Rimon N, et al. Evaluation of screening for hepatitis $B$ surface antigen during pregnancy in a population with a high prevalence of hepatitis B surface antigen-positive/ hepatitis B e antigennegative carriers. Pediatr Infect Dis J. 1999; | 8:262-6.

13.Freitas da Motta MS, Mussi-Pinhata MM, Jorge SM, Tachibana Yoshida CF, Sandoval de Souza CB. Immunogenicity of hepatitis B vaccine in preterm and full term infants vaccinated within the first week of life. Vaccine. 2002;20: I 557-62. 14.Succi RCM, Machado DM, Nunes AMB, Weckx LY. Soroconversão após vacina recombinante contra hepatite B em crianças expostas ao HIV. In: XII Congresso Brasileiro de Infectologia Pediátrica; 2000; Rio de Janeiro. Anais. p.39.

15.Scaramuzzi DR. Eficácia da imunoprofilaxia na prevenção da transmissão perinatal da hepatite pelo vírus B em recém-nascidos de mães portadoras do vírus B e positivas para o AgHBe: metanálise [dissertação]. São Paulo: Faculdade de Medicina, Universidade de São Paulo; 2002. 